\title{
Hypotension in patients with coronary disease: can profound hypotensive events cause myocardial ischaemic events?
}

\author{
P Owens, E O’Brien
}

\begin{abstract}
Objective-To determine whether anginal episodes might be related to extremes of hypotension in patients with ischaemic heart disease taking drugs to treat angina and heart failure.

Design and setting-Observational study of patients with ischaemic heart disease attending an urban tertiary referral cardiology centre.
\end{abstract}

Interventions and outcome measures-A selected patient population was enrolled, having: angina on one or more hypotensive cardiovascular medications; hypotension on clinic or ambulatory measurement; and a resting ECG suitable for ambulatory monitoring. Patients had echocardiography, ambulatory blood pressure monitoring, and Holter monitoring. Hypotension induced ischaemic (HII) events were defined as episodes of ST segment ischaemia occurring at least one minute after an ambulatory blood pressure measurement (systolic/diastolic) below $100 / 65 \mathrm{~mm} \mathrm{Hg}$ during the day, or $90 / 50 \mathrm{~mm} \mathrm{Hg}$ at night.

Results-25 suitable patients were enrolled, and 107 hypotensive events were documented. $40 \mathrm{ST}$ events occurred in 14 patients, of which a quarter were symptomatic. Fourteen HII events occurred in eight patients, with 13 of the 14 preceded by a fall in diastolic pressure (median diastolic pressure $57.5 \mathrm{~mm} \mathrm{Hg}$, interquartile range 11 , maximum $72 \mathrm{~mm} \mathrm{Hg}$, minimum $45 \mathrm{~mm} \mathrm{Hg}$ ), and six preceded by a fall in systolic pressure $\left(\chi^{2}=11.9\right.$, p < 0.001). ST events were significantly associated with preceding hypotensive events $\left(\chi^{2}=40.2, \mathrm{p}<0.0001\right)$. Patients with HII events were more frequently taking multiple hypotensive drug regimens $\left(8 / 8 v 9 / 17, \chi^{2}=5.54, p=0.022\right)$.

Conclusions-In patients with ischaemic heart disease and hypotension, symptomatic and silent ischaemia occurred in a temporally causal relation with hypotension, particularly for diastolic pressures, suggesting that patients with coronary disease may be susceptible to ischaemic events incurred as a result of low blood pressure caused by excessive hypotensive drug treatment.

(Heart 1999;82:477-481)

Keywords: ischaemic heart disease; hypotension; drug treatment
A growing number of patients with ischaemic heart disease are treated with multidrug regimens of antianginal and anti-heart failure medication, either before definitive revascularisation interventions, or in the context of inoperable coronary disease. Virtually all of these medications can cause hypotension.

Work in animal models and some human data suggest that coronary blood flow autoregulatory mechanisms may fail below certain critical blood pressure values. ${ }^{1-3}$ The level of pressure at which flow becomes compromised is increased in conditions where there is an intracoronary flow gradient, such as the presence of a stenotic coronary plaque, and in conditions where high intramural pressures are present, such as left ventricular hypertrophy or a high end diastolic left ventricular pressure. ${ }^{3-7}$

Intractable angina in these patients is usually attributed to either inadequate dosing or ineffectiveness of prescribed drugs. We propose a third possibility-that extremes of hypotension may potentially cause ischaemic events in these patients. We tested this hypothesis by examining simultaneous blood pressure and ECG data in a selected cohort of patients with coronary disease and documented hypotension.

\section{Methods}

PATIENT POPULATION

The observational cohort was enrolled from patients attending the cardiology unit in our institution, after giving informed consent. The study protocol was approved by the hospital ethics committee. Patients were selected if they had angiographically documented ischaemic heart disease, and were either awaiting definitive medical or surgical revascularisation, or were deemed unsuitable for these procedures. Also patients had to have symptoms of angina pectoris despite medical treatment. Patients had to be on treatment with at least one cardiovascular drug known to reduce blood pressure. Furthermore, patients had to have exhibited clinical hypotension, with either a clinic or a ward measured pressure showing persistent readings below $100 \mathrm{~mm} \mathrm{Hg}$ systolic or $65 \mathrm{~mm} \mathrm{Hg}$ diastolic, or an ambulatory blood pressure monitor showing hypotensive events below $100 \mathrm{~mm} \mathrm{Hg}$ systolic, $65 \mathrm{~mm} \mathrm{Hg}$ diastolic, or both, during the day, or below $90 \mathrm{~mm} \mathrm{Hg}$ systolic, $50 \mathrm{~mm} \mathrm{Hg}$ diastolic, or both, during the night. Patients satisfying the above criteria were considered suitable. Exclusion criteria were: left bundle branch block on ECG; concurrent digoxin treatment; atrial 
fibrillation; documented intra-arm difference in blood pressure greater than $10 \mathrm{~mm} \mathrm{Hg}$; and failure to obtain informed consent.

ECHOCARDIOGRAPHY

Echocardiography was performed using a Hewlett-Packard Sonos 100CF echocardiography imaging system (Andover, Massachusetts, USA), with a $2.5 \mathrm{MHz}$ transducer applied to the anterior chest wall, recording parasternal long axis, short axis, and apical views. Left ventricular dimensions were calculated from onscreen $M$ mode tracings taken at the level of the mitral valve tips. Left ventricular mass was calculated using the formula of Devereux and colleagues. ${ }^{7}$ The ejection fraction was calculated using volume measurements from the apical four chamber view of the left ventricle.

CLINIC BLOOD PRESSURE

On arrival for study, the patient lay quietly on a study couch for five minutes, and had blood pressure measured in both arms using an Omron HEM 705CP automated blood pressure monitor. The patient was then asked to stand, and had blood pressure measured again in the non-dominant arm after one minute and five minutes standing unsupported. A postural drop in blood pressure was defined as a fall of $20 \mathrm{~mm} \mathrm{Hg}$ systolic or $10 \mathrm{~mm} \mathrm{Hg}$ diastolic between the supine and the erect measurement.

AMBULATORY BLOOD PRESSURE MONITORING

Ambulatory blood pressure monitoring was performed using the SpaceLabs 90207 ambulatory blood pressure monitor (Redmond, Washington, USA). ${ }^{8}$ This was fitted to the non-dominant arm after arm measurement for appropriate cuff size, and the monitor was programmed for measurement at 15 minute intervals, day and night. The patient was instructed to continue life as normal between readings, but to rest the arm at heart level during readings. Patients were also asked to keep an accurate symptom diary, reporting activity at each measurement, and, in particular, noting symptoms consistent with angina pectoris. They were also asked to note down the time of taking their medication, time of retiring, and time of rising. The night time period was defined according to the diary card entry for rising and retiring. All patients attended the blood pressure unit for removal of the monitor, and the data were downloaded from the ambulatory blood pressure monitor and immediately uploaded into a specialised software database. ${ }^{9}$ All recorded measurements not edited by the monitor software were included in the results. ${ }^{10}$

\section{AMBULATORY ECG MONITORING}

The Holter monitor used was a Tracker 2 two channel device. The monitor was fitted at the same time as the ambulatory blood pressure monitor, after meticulous skin preparation and affixing of the electrodes in order to give a modified lead aVF and V5. The recorder time was noted, and the ambulatory blood pressure monitor time was adjusted to give a simultane- ous time display. Both monitors were worn on a belt around the patient's waist, and the patient was asked to refer to the ambulatory blood pressure monitor time display for noting symptoms. The monitor was removed the next day at the same time as the ambulatory blood pressure monitor, and the recorded tape was analysed using a Reynolds Medical Pathfinder 6 Holter tape analyser (Hertford, UK). The recording was visually inspected in its entirety, and the isoelectric line was identified for a normal period of ST segment activity. The recording was analysed for arrhythmia and ST segment depression. A significant ischaemic event was defined as ST depression below the isoelectric line $\geqslant 100 \mu \mathrm{V}$, lasting one minute or longer, and separated from a similar episode by at least one minute.

DEFINITIONS AND STATISTICS

A hypotensive event was defined as: a drop in systolic pressure below $100 \mathrm{~mm} \mathrm{Hg}$, or diastolic pressure below $65 \mathrm{~mm} \mathrm{Hg}$, during the daytime period, lasting for at least two consecutive measurements; or a fall in systolic pressure below $90 \mathrm{~mm} \mathrm{Hg}$, or diastolic pressure below $50 \mathrm{~mm} \mathrm{Hg}$, during the night time period, lasting for at least two consecutive measurements. These values are based on the fifth centile of blood pressure taken from a large normal population ambulatory blood pressure database. ${ }^{11}$ The onset of the hypotensive event was taken as the first hypotensive reading, appropriate to the lower limit of normal for daytime or night time. A hypotension induced ischaemic (HII) event was defined as an episode of ST depression, occurring during a hypotensive episode, where the start of the ST event occurred at least one minute after the start of the hypotensive event, and where resolution of the ST event occurred after, or coincident with, the normalisation of the blood pressure tracing.

The data throughout are presented as mean (SD) or median (interquartile range) where appropriate. Continuous variables were compared using the Student's $t$ test; categorical associations were analysed using the $\chi^{2}$ test.

\section{Results}

A total of 25 suitable patients were recruited over a six month period, satisfying the protocol criteria. The population had a mean age of 63

Table 1 Clinical characteristics of the patient population (values are medians, unless otherwise specified)

\begin{tabular}{ll}
\hline Number of patients & 25 \\
Mean (SD) age (years) & $63(9.7)$ \\
Sex (M/F) & $19 / 6$ \\
Mean (SD) body mass index $\left(\mathrm{g} / \mathrm{m}^{2}\right)$ & $28(7.7)$ \\
Extent of coronary disease (number of diseased & \\
$\quad$ vessels) & 2 \\
Number of different hypotensive medications per & \\
$\quad$ day & 2 \\
CCS class & 2 \\
NYHA class & 1 \\
Mean (SD) left ventricular ejection fraction & $45(12.5)$ \\
Patients with past history of hypertension & \\
$\quad$ (number/total) & $10 / 25$ \\
Echocardiographic left ventricular hypertrophy & $8 / 25$ \\
\hline
\end{tabular}

CCS, Canadian Cardiovascular Society index for severity of angina; NYHA, New York Heart Association index for severity of heart failure symptoms. 
Table 2 Drug treatment for study population. Where two or more patients were taking the same medication at different doses, the dose shown is the mean

\begin{tabular}{|c|c|c|c|c|c|c|}
\hline & $\begin{array}{l}\text { Number of } \\
\text { patients }\end{array}$ & Nitrate & $\beta$ blocker & Calcium antagonist & ACE inhibitor & Diuretic \\
\hline Monotherapy & 8 & $2 \times$ ISMN $60 \mathrm{mg}$ od & $\begin{array}{l}\text { Metoprolol } 50 \mathrm{mg} \text { bid } \\
\text { Atenolol } 100 \mathrm{mg} \text { od } \\
\text { Selectol } 200 \mathrm{mg} \mathrm{od} \\
2 \times \text { sotalol } 80 \mathrm{mg} \mathrm{bid}\end{array}$ & Diltiazem $90 \mathrm{mg}$ bid & & \\
\hline Dual therapy & 13 & $\begin{array}{l}5 \times \text { ISMN } 60 \mathrm{mg} \text { od } \\
1 \times \text { nitrate patch } 10 \mathrm{mg} \\
\text { od }\end{array}$ & $\begin{array}{l}5 \times \text { metoprolol } 50 \mathrm{mg} \\
\text { bid } \\
2 \times \text { sotalol } 80 \mathrm{mg} \mathrm{bid}\end{array}$ & $\begin{array}{l}4 \times \text { diltiazem } 90 \mathrm{mg} \text { bid } \\
1 \times \text { nicardipine } 20 \mathrm{mg} \\
\text { tid }\end{array}$ & $\begin{array}{l}2 \times \text { lisinopril } 15 \mathrm{mg} \\
\text { od } \\
2 \times \text { enalapril } 10 \mathrm{mg} \\
\text { od } \\
\text { Captopril } 24 \mathrm{mg} \text { bid }\end{array}$ & $\begin{array}{l}3 \times \text { frusemide/amiloride } 40 / 5 \\
\mathrm{mg} \text { od }\end{array}$ \\
\hline Triple therapy & 4 & $4 \times \mathrm{ISMN} 60 \mathrm{mg}$ od & $\begin{array}{l}\text { Metoprolol } 50 \mathrm{mg} \text { bid } \\
\text { Atenolol } 100 \mathrm{mg} \text { od }\end{array}$ & $3 \times$ diltiazem $90 \mathrm{mg}$ bid & $\begin{array}{l}\text { Captopril } 25 \mathrm{mg} \text { bid } \\
\text { Lisinopril } 20 \mathrm{mg} \text { od }\end{array}$ & $\begin{array}{l}\text { Frusemide/amiloride } 40 / 5 \mathrm{mg} \\
\text { od }\end{array}$ \\
\hline
\end{tabular}

ISMN, isosorbide mononitrate; ACE, angiotensin converting enzyme.

(9.7) years, and was predominantly male. Table 1 summarises the clinical characteristics of the population. Drug treatment for the group is summarised in table 2 .

\section{BLOOD PRESSURE}

Mean supine resting systolic/diastolic blood pressure was $131(24) / 77$ (11) $\mathrm{mm} \mathrm{Hg}$. Twenty patients exhibited a fall in systolic blood pressure on standing at five minutes (mean 12 (14) $\mathrm{mm} \mathrm{Hg}, \mathrm{p}<0.001$ ), while 13 patients showed a fall in diastolic blood pressure at five minutes' standing (mean 2 (9) $\mathrm{mm} \mathrm{Hg}$, $\mathrm{p}=\mathrm{NS}$ ). The ambulatory data were complete for all patients except one, who removed the monitor during the night time period. There were 107 hypotensive events in total, 46 involving simultaneous falls in both systolic and diastolic pressure. A further 44 events were isolated falls in diastolic pressure, and 17 events were isolated falls in systolic pressure. The blood pressure data are presented in table 3. Extremes of blood pressure were achieved, with the nadir systolic blood pressure reaching $70 \mathrm{~mm} \mathrm{Hg}$, while the nadir diastolic blood pressure reached $30 \mathrm{~mm} \mathrm{Hg}$.

AMBULATORY ECG MONITORING

Holter monitoring was complete for all patients. No serious arrhythmia was documented on any tracing. Forty ST segment events consistent with ischaemia were noted in 14 patients. The median number of events in patients who exhibited ST events was 2.5 (3.5). Symptoms attributable to myocardial ischaemia occurred in 10 of the 40 episodes of ST changes, the remaining 30 therefore having silent ischaemic events. The number of ST events occurring between the hours of 03:00 and 10:00 was 17; ST events, however, did not occur significantly more frequently during the early morning.
HYPOTENSION INDUCED ISCHAEMIA

A total of 14 ST events in eight patients met the criteria for an HII event. For the remaining 26 ST events, blood pressure remained above the lower limit of normal. There was a highly significant association between ischaemic events and an immediately preceding hypotensive event $\left(\chi^{2}=40.2, \mathrm{p}<0.0001\right)$. Two patients had three HII events each, two patients had two events each, and four patients had one event. Nine occurred during the daytime and five occurred during sleep. Of these $14 \mathrm{HII}$ events, 13 were preceded by diastolic pressures below $65 \mathrm{~mm} \mathrm{Hg}$ (median diastolic pressure 57.5 (interquartile range 11, maximum $72 \mathrm{~mm} \mathrm{Hg}$, minimum $45 \mathrm{~mm} \mathrm{Hg}$ )), while only six were preceded by systolic pressures below $100 \mathrm{~mm} \mathrm{Hg}$ (median systolic pressure $102 \mathrm{~mm} \mathrm{Hg}$ (interquartile range 31.25 , maximum $133 \mathrm{~mm} \mathrm{Hg}$, minimum $80 \mathrm{~mm} \mathrm{Hg}$ )) $\left(\chi^{2}=11.9, \mathrm{p}<0.001\right)$. In each patient who showed an HII event, diastolic pressure at onset was lower than the mean diastolic pressure for all non-HII events in the remainder of that patient's blood pressure tracing, in all cases but one. Pressures at onset of HII events were significantly lower than at the onset of non-HII ST events (diastolic 56 (7.5) $v 73$ (6.0) $\mathrm{mm} \mathrm{Hg}, \mathrm{p}<0.0001$; systolic 103 (16.5) v 116 (12.9) $\mathrm{mmHg}, \mathrm{p}=0.017$ ).

HII events were more likely to occur in patients taking two or more hypotensive drugs (8/8 patients with HII $v 9 / 17$ patients without HII, $\chi^{2}=5.54, p=0.022$, Fisher's exact test). No individual drug class was significantly more frequently represented in the HII group.

Table 4 shows comparisons of clinical variables between patients with and without HII events. Patients with HII events were slightly older and had more severe ischaemic symptomatology. Echocardiographic parameters did not differ significantly between the two groups. Interestingly, orthostatic hypotension, defined as

Table 3 Ambulatory blood pressure monitoring data for study population

\begin{tabular}{|c|c|c|c|c|c|c|}
\hline & Mean & $S D$ & Median & $I Q R$ & Minimum & Maximum \\
\hline Mean day SBP & 117 & 13 & 115 & 19 & 99 & 147 \\
\hline Mean day DBP & 72 & 6 & 73 & 9 & 58 & 84 \\
\hline Mean night SBP & 108 & 17 & 106 & 24 & 86 & 148 \\
\hline Mean night DBP & 63 & 9 & 61 & 10 & 51 & 92 \\
\hline Hypotensive events (systolic) & & & 1 & 3.5 & 0 & 9 \\
\hline Hypotensive events (diastolic) & & & 4 & 5 & 0 & 12 \\
\hline Nadir SBP & 88 & 11 & 86 & 16 & 70 & 112 \\
\hline Nadir DBP & 49 & 7 & 48 & 7 & 30 & 64 \\
\hline
\end{tabular}

SBP, systolic blood pressure; DBP, diastolic blood pressure; IQR, interquartile range. 
Table 4 Comparisons of clinical variables between patients with and without hypotensive induced ischaemic (HII) events. Continuous variables are compared using t test, categorical variables compared using $\chi^{2}$ test/Fisher's exact test

\begin{tabular}{llll}
\hline & HII events & Non-HII events & $p$ \\
\hline Age & $70(7.6)$ & $61(8.9)$ & 0.02 \\
Sex $(\mathrm{M} / \mathrm{F})$ & $5 / 3$ & $14 / 3$ & $\mathrm{NS}$ \\
Body mass index $\left(\mathrm{g} / \mathrm{m}^{2}\right)$ & $27(4.4)$ & $28(8.9)$ & $\mathrm{NS}$ \\
Day SBP (mm Hg) & $117(13.5)$ & $118(12.6)$ & $\mathrm{NS}$ \\
Day DBP (mm Hg) & $71(5.5)$ & $72(6.7)$ & $\mathrm{NS}$ \\
Night SBP (mm Hg) & $107(19.5)$ & $108(15.8)$ & $\mathrm{NS}$ \\
Night DBP (mm Hg) & $62(9.0)$ & $64(9.5)$ & $\mathrm{NS}$ \\
Number of medications $(1,2,3)$ & $0,4,4$ & $8,9,0$ & 0.002 \\
Orthostatic hypotension (number/total) & $5 / 8$ & $4 / 17$ & 0.07 \\
Ejection fraction & $42(16)$ & $46(11)$ & $\mathrm{NS}$ \\
Left ventricular hypertrophy & $2 / 8$ & $6 / 17$ & $\mathrm{NS}$ \\
1, 2, 3 vessel disease & $1,5,2$ & $3,5,9$ & $\mathrm{NS}$ \\
CCS (class I, II, III) & $0,0,8$ & $6,10,1$ & $<0.001$ \\
NYHA (class I, II, III) & $4,3,1$ & $13,3,1$ & $\mathrm{NS}$ \\
\hline
\end{tabular}

a fall of either $20 \mathrm{~mm} \mathrm{Hg}$ systolic or $10 \mathrm{~mm} \mathrm{Hg}$ diastolic between supine blood pressure and blood pressure at five minutes' standing, was more commonly found in patients exhibiting hypotension induced ischaemia, although this trend did not quite reach significance.

\section{Discussion}

A significant number of patients continue to suffer ongoing angina pectoris despite medical treatment. The initial response to continued symptomatology is to increase antianginal drug dosing. Not infrequently this can cause a significant fall in blood pressure, and symptoms of fatigue, weakness, and orthostatic dizziness may occur. In the context of significant drops in perfusion pressure, it is possible that end organ perfusion may be suboptimal in the presence of stenotic arterial disease. Accordingly, we postulated that myocardial ischaemia was induced by very low blood pressures.

We have shown that, in our highly selected population of patients with ischaemic heart disease, intractable angina, and hypotension, episodes of both symptomatic and silent ischaemia were preceded by falls in blood pressure to levels below the fifth centile of normal, appropriate for time of day. Further, it has been shown that these falls were almost invariably in diastolic pressure, and that the patients in whom these extremes of pressure were reached were taking more hypotensive medication than those free from these events. Finally, the recorded pressures at the outset of these events were the lowest pressures reached by these patients during the recording period.

To our knowledge, this is the first systematic study in the literature showing this association. Anecdotal reports have suggested hypotension as a contributory factor in some cases of ischaemic chest pain, ${ }^{12}{ }^{13}$ and one report has documented an association between ischaemic episodes in treated hypertensive patients and nocturnal "overdipping", representing relative nocturnal hypotension. ${ }^{14}$ This phenomenon may in part explain the "J shaped curve" effect seen in overtreated hypertensives, ${ }^{15}$ who not infrequently have concomitant ischaemic heart disease, where mortality from cardiovascular causes rises with diastolic blood pressure reduction below $80 \mathrm{~mm} \mathrm{Hg}$.

Central to the study interpretation here is the concept of causality. As an observational study, this can only suggest association, and accordingly cannot be taken as definitive proof of hypotensive events provoking myocardial ischaemia. However, there are strong reasons for making this interpretation. It was a requirement that an HII event could only be diagnosed if the onset of ST depression occurred after a documented hypotensive reading. The possibility that myocardial ischaemia caused a reduction in myocardial contractility and, therefore, a fall in blood pressure is obviously an alternative explanation, but this is unlikely for a number of reasons. Firstly, the requirement for hypotension to precede ECG ischaemia gives an obvious temporal direction to the hypotension-ischaemia link. Further, one might expect ischaemia induced myocardial impairment to affect systolic pressure preferentially, whereas it was primarily diastolic pressure that fell in our population. Finally, if myocardial ischaemia was the cause of hypotension, one would expect those on maximum anti-ischaemic treatment to have the lowest incidence of ischaemia induced hypotension, whereas our findings were the opposite.

How can one explain the association between hypotension and ischaemia? The concept of coronary autoregulation of blood flow explains how myocardial perfusion is maintained in the face of variations in perfusion pressure. ${ }^{16}$ In the case of coronary arteries, perfusion pressure is identical to ascending aortic diastolic pressure. The flow in coronary arteries is dependent on pressure, and a coronary plaque causing a significant stenosis in an artery gives rise to a trans-stenotic, intracoronary gradient. Autoregulatory mechanisms may fail in the context of coronary stenoses to maintain adequate forward flow in the face of reductions in perfusion pressure. ${ }^{17}$ Accordingly, extreme reductions in diastolic pressure may be sufficient to exceed autoregulatory compensation, leading to perfusion defects and ischaemia. The association with multiple drug regimens could then be interpreted in the context of excessive reductions in blood pressure. Also, there is evidence that the response of the coronary artery to vasodilatory drugs may be altered in the presence of atherosclerosis. Both the calcium channel blocker nifedipine and $\beta$ blockers ${ }^{18} 19$ have been shown to have an obtunded vasodilatory effect on atherosclerotic arteries which, in the context of normal dilatory response of the artery proximal to a stenosis, may worsen coronary flow resistance and exacerbate distal ischaemia in the presence of diastolic hypotension.

Other data exist to support the hypothesis of hypotension induced ischaemia, in particular from the anaesthetic literature. Myocardial ischaemia has been described as occurring in patients who developed hypotension in response to isoflurane-nitrous oxide anaesthesia. ${ }^{20}{ }^{21}$ This was felt to reflect a steal prone coronary anatomy. Established coronary disease involves the formation of collaterals in the myocardial bed, and in the context of reduction in blood flow, larger non-diseased vessels, where resistance to flow is least, may preferentially "steal" blood flow from more 
compromised areas. ${ }^{22}{ }^{23}$ Such blood pressure dependent steal phenomena are well established in the neurological circulation. ${ }^{24}$ In the swine model, however, non-steal prone coronary vascular stenosis models have shown ischaemic changes in the myocardium secondary to anaesthesia induced hypotension. ${ }^{25}$ Also, more direct evidence of hypotension induced ischaemia comes from a study showing that myocardial ischaemia, refractory to standard nitrate treatment, can be reversed by increasing blood pressure with the vasopressor agent metaraminol. ${ }^{26}$ It is speculated that extreme hypotension might give rise to a flow dependent collapse in stenotic coronary arteries. ${ }^{27}$ Finally, there is evidence that pharmacologically induced hypotension with short acting calcium channel blockers can initiate ischaemia in patients who have an obtunded tachycardic response to low blood pressure by virtue of concomitant treatment with $\beta$ blockers. ${ }^{13}$

A number of caveats must be considered in reference to these data. Firstly, the study population is a highly select one, demonstrating notable hypotension and ischaemic symptomatology, and on polypharmacy prescriptions. The results cannot be generalised to the ischaemic population at large without caution. Secondly, to conclude that drug treatment has been solely responsible for initiating hypotensive events is not necessarily correct; a significant proportion of the patients with HII events had postural hypotension, and it may be that the falls in blood pressure may have a contributory factor from autonomic neuropathic mechanisms.

In conclusion, we have shown a likely causal relation between hypotensive events, primarily for diastolic pressure, and both symptomatic and asymptomatic coronary ischaemia, in patients with obstructive coronary disease and drug related low blood pressure. This opens the concept of overtreatment of patients with ischaemic heart disease as a pathologically important factor in their management.

The authors wish to acknowledge the Charitable Infirmary Charitable Trust for continued support, and the Royal College of Surgeons in Ireland, Beaumont Hospital, and the Blood Pressure Unit for additional support.

1 Dole W. Autoregulation of the coronary circulation. Prog Cardiovasc Dis 1987;29:293-323.

2 Klocke FJ. Measurements of coronary flow reserve: defining pathophysiology versus making decisions about patien care. Circulation 1987;76:1183-9.

3 Pepi M, Alimento M, Maltagliati A, et al. Cardiac hypertrophy in hypertension: repolarisation abnormalities elicited by rapid lowering of pressure. Hypertension 1988;11:84ited

Vogt M, Motz W, Strauer BE. Coronary haemody:84-91. hypertensive heart disease. Eur Heart $f$ 1992;13(suppl D):44-9.
5 Polese A, De Cesare N, Montorsi P, et al. Upward shift of the lower range of coronary flow autoregulation in hypertensive patients with hypertrophy of the left ventricle. Circulation 1991;83:845-53.

6 Trenkwalder P, Dobrindt R, Plaschke M, et al. Usefulness of simultaneous ambulatory electrocardiographic and blood pressure monitoring in detecting myocardial ischaemia in patients $>70$ years of age with Cardiol 1993;72:927-31.

7 Devereux RB, Lutas EM, Casale PN, et al. Standardisation of $\mathrm{M}$-mode echocardiographic left ventricular anatomic measurements. F Am Coll Cardiol 1984;4:1222-30.

8 O'Brien E, Mee F, Atkins N, et al. Accuracy of the SpaceLabs 90207 determined by the British Hypertension Society protocol. F Hypertens 1991;9:573-4.

9 Atkins N, Mee F, O'Brien E. A customised international database system for storing and analysing ambulatory blood pressure measurements and related data [abstract]. $\mathcal{F}$ Hypertens 1994;12:S23.

10 Staessen JA, Fagard R, Thijs L, et al and the participants in the Fourth International Consensus Conference on 24hour Ambulatory Blood Pressure Monitoring. A consensus view on the technique of ambulatory blood pressure monitoring. Hypertension 1995;26:912-8.

11 O'Brien E, Murphy J, Tyndall A, et al. Twenty-four-hour ambulatory blood pressure in men and women aged 17 to 80 years: the Allied Irish Bank study. $\mathcal{F}$ Hypertens 1991;9:355-60.

12 Burckharrt BA, Mukerji V, Alpert MA. Coronary artery slow flow associated with angina pectoris and hypotension: a case report. Angiology 1998;49:483-7.

13 Boden WE, Korr KS, Bough EW. Nifedipine-induced hypotension and myocardial ischaemia in refractory angina pectoris. $7 A M A$ 1985;253:1131-5.

14 Pierdomenico SD, Bucci A, Costantini F, et al. Circadian blood pressure changes and myocardial ischaemia in hypertensive patients with coronary artery disease. $7 \mathrm{Am}$ Coll Cardiol 1998;31:1627-34.

15 Cruickshank JM, Thorp JM, Zacharias FJ. Benefits and potential harm of lowering blood pressure. Lancet 1987;i: $581-4$.

16 Gould KL. Quantification of coronary artery stenosis in vivo. Circ Res 1985;57:341-53.

7 Cruickshank JM. The role of coronary perfusion pressure. Eur Heart $\mathcal{7}$ 1992;13(suppl D):39-43.

18 Raby KE, Vita JA, Rocco MB, et al. Changing vasomotor responses of coronary arteries to nifedipine. Am Heart $\mathcal{F}$ 1993;126:333-8.

19 Berkenboom G, Unger P, Fontaine J. Atherosclerosis and responses of human isolated coronary arteries to endothelium-dependent and independent vasodilators. $\mathcal{F}$ Cardiovasc Pharmacol 1989;14(suppl 11):S35-9.

20 Reiz S, Ostman M. Regional coronary haemodynamics during isoflurane-nitrous oxide anaesthesia in patients with ischaemic heart disease. Anaesthesia and Analgesia 1985;64: $570-6$.

21 Khambatta HJ, Sonntag H, Larsen R, et al. Global and regional myocardial blood flow and metabolism during equipotent halothane and isoflurane anaesthesia in patients with coronary artery disease. Anaesthesia and Analgesia 1988;67:936-42

22 Chiariello M, Gold HK, Leinbach RC, et al. Comparison between the effects of nitroprusside and nitroglycerin on ischaemic injury during acute myocardial infarction. Circulation 1976:54:766-73.

23 Armstrong PW, Walker DC, Burton JR, et al. Vasodilator therapy in acute myocardial infarction: a comparison of sodium nitroprusside and nitroglycerin. Circulation 1975; 52:1118-22

24 Finnerty FA Jr, Witkin L, Fazekas JF. Cerebral haemodynamics during cerebral ischaemia induced by acute hypotension. F Clin Invest 1959;33:1227.

25 Mergner GW, Stolte AL, Frame WB, et al. Combined epidural analgesia and general anaesthesia induce ischaemia distal to a severe coronary artery stenosis in swine. Anaesthesia and Analgesia 1994;78:37-45.

26 Figueras J, Lidon RM, Cortadellas J. Metaraminol-induced reversal of acute myocardial ischaemia associated with hypotension and refractory to intravenous nitroglycerin. Eur Heart $\mathcal{F}$ 1991;12:720-5.

27 Logan SE. On the fluid mechanics of human coronary artery stenoses. IEEE Trans Biomed Eng 1975;22:327-35. 